\title{
Gilberto Freyre e a nova história
}

\author{
PETERBURKE
}

RESUMO: O ponto de partida deste artigo é uma série de semelhanças entre a 'nova história' associada aos Annales e a história social, psico-história ou antropologia histórica de Gilberto Freyre; semelhanças que vão desde um interesse pela cultura material (alimentação, vestimenta e habitação) até um interesse pelas mentalidades e pela história da infância, tema que preocupou Freyre antes da publicação de Casa-grande \& senzala. Estas semelhanças de abordagem foram reconhecidas tanto por Febvre como por Braudel quando descobriram a obra de Freyre no fim dos anos 30. Freyre, no entanto, não estava imitando o Annales e nem Febvre ou Braudel o estavam imitando. Freyre aprendera seu estilo interdisciplinar na Universidade Columbia, um centro do movimento americano da 'nova história' no início do século. Por outro lado, assim como Febvre, Freyre também admirava Michelet. Já a 'história íntima' de Freyre é, em algum grau, devedora da Histoire Intime praticada pelos irmãos Goncourt, uma história cuja importância para a história da historiografia ainda não foi suficientemente reconhecida.

ste ensaio é uma tentativa de investigar um paralelo que não recebeu a merecida atenção, o paralelo entre a chamada "nova história" pregada e praticada na França a partir da década de 60 e a história que Gilberto Freyre escreveu a partir da década de $30^{1}$.

Uma característica central da nouvelle histoire francesa foi seu foco em "novos objetos", para citar o título de um volume que explica e exemplifica o movimento (cf. Le Goff \& Nora, 1974, 1). A história da cultura mate-
UNITERMOS: historiografia, psico-história, antropologia histórica, cultura material, mentalidades.
Professor da Faculdade de História da Universidade de Cambridge e Fellow de Emmanuel College 
${ }^{1}$ Versões anteriores deste ensaio foram apresentadas no seminário A obra em tempos vários: 95 anos de Gilberto Freyre, Recife, maio de 1995 , e na conferência da Brazilian Studies Association (BRASA), realizada em Cambridge, de 7 a 10 de setembro de 1996. Desejo agradecer à audiência por suas questões e comentários.

${ }^{2}$ Cf. Revel e Peter (1974); Flandrin (1975; 1983); Ariès e Duby (1987-1991); Duby e Perrot (1992-1994).

3 Diário de Pernambuco, 30 de setembro de 1923. Reproduzido em Freyre (1979, p. 315). rial (civilisation matérielle), por exemplo, foi investigada por Fernand Braudel na década de 60 (cf. Braudel, 1967; Burke, 1981). Os seguidores de Braudel continuaram seus estudos sobre alimentação, habitação, vestuário e assim por diante (cf. Hemandiquer, 1970; Bardet et alii, 1971; Ladurie, 1975; Roche, 1989). Seguindo a liderança de Georges Duby e Philippe Ariès, a história da família foi ampliada de modo a incluir a história da vida privada, a história do amor, a história da sexualidade, a história do corpo e finalmente, com o despertar do movimento feminista, a história das mulheres ${ }^{2}$.

Todos esse tópicos foram estudados não apenas do ponto de vista econômico e social, mas também do ponto de vista da cultura (no sentido amplo do termo), da "psicologia histórica" ou da "história das mentalidades coletivas". Robert Mandrou, por exemplo, apresentou seu trabalho sobre o início da França moderna como "psicologia histórica", enquanto Michel Vovelle, um pioneiro na história da morte, situava seu trabalho na fronteira entre as mentalidades e as ideologias (cf. Mandrou, 1964; Vovelle, 1982).

A história da infância de Philippe Ariès é um dos mais famosos exemplos da nova abordagem do passado. Pode-se dizer que Ariès inventou a história da infância ao proclamar que a idéia de infância não existia na Idade Média, mas foi inventada no início da França moderna. Ele não foi um profissional, mas um "historien de dimanche", como ele descreveu a si próprio em sua autobiografia (cf. Ariès, 1982). De qualquer modo, seu estudo sobre a infância, assim como aquele posterior sobre a morte, reflete o interesse na história das "mentalidades coletivas" associada à escola ou ao grupo dos Annales. Seu livro é admirável pelo uso da evidência iconográfica e pela preocupação com a cultura material (notadamente roupas e brinquedos) enquanto expressões de mudanças nas atitudes dos adultos para com as crianças (cf. Ariès, 1960).

Entretanto, como se sabe, todos esses tópicos foram discutidos um geração antes por Gilberto Freyre, especialmente em seus estudos sobre o Brasil colonial. A principal razão para seu interesse na arquitetura vernacular foi explicada por Freyre em alguns artigos de jornal da década de 20. "Há casas cujas fachadas indicam todo um gênero de vida nos seus mais íntimos pormenores. Todo um tipo de civilização. O 'bungalow' americano é assim"

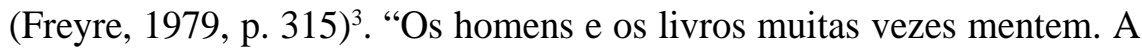
arquitetura quase sempre diz a verdade através de seus sinais de dedos de pedra" (Freyre, 1935, p. 82).

A importância da habitação em Casa-grande \& senzala e em Sobrados e mucambos é indicada pelos títulos assim como pelos conteúdos desses livros. Também em estudos posteriores, Freyre escreveu sobre as variações na edificação como sendo expressões de variações na cultura. Ordem e Progresso, por exemplo, inclui várias páginas sobre o chalé. Um estudo da década de 70 defendeu o trabalho do autor contra os críticos e tentou uma síntese das abordagens antropológica, histórica e sociológica da habitação de seus livros anteriores (cf. Freyre, 1941b, p. 168 ss, 215-227; 1959, 1, p. 213 
ss; 1971). Falta apenas que alguém atualize sua história social com estudos da história social da favela, do condomínio e talvez do shopping.

Os conteúdos da casa tampouco foram negligenciados. Na década de 60, Braudel escreveu passagens famosas sobre a história social de cadeiras e mesas. Na década de 30, Freyre refletiu sobre a história cultural da rede e da cadeira de balanço, símbolos da voluptuosa ociosidade que os brasileiros em geral - ele sugeriu - herdaram dos colonos de Pernambuco (cf. Freyre, 1933; 1937, p. 219). Tópicos como esses, que haviam sido considerados superficiais ou triviais, foram vistos por ambos historiadores como chaves para as estruturas subjacentes às diferentes culturas.

A história da alimentação é outro tema recorrente - para não dizer obsessão - nos ensaios de Freyre, que freqüentemente tecem elogios às tradições culinárias de Pernambuco, especialmente seus doces. Ele dedicou até mesmo uma pequena monografia ao assunto, combinando uma lista de receitas com reflexões sobre "etnografia, história e sociologia" de seus doces favoritos (cf. Freyre, 1925; 1939). Enquanto historiador social, Freyre examinou a alimentação a partir de dois ângulos principais. O primeiro foi o da dieta, especialmente de suas insuficiências; o segundo, o da significação simbólica dos vários tipos de comidas enquanto expressão de valores como hospitalidade, masculinidade e feminilidade, tais como definidos pela cultura colonial do Nordeste. Em algumas das mais admiráveis páginas de Sobrados $e$ Mucambos, Freyre discute os regimes alimentares da "virgem pálida" e da "esposa gorda e bonita" (cf. Freyre, 1933, p. 237 ss; 1936, p. 140 ss).

Como se poderia esperar de um livro cujo tema central é "a formação da família brasileira" (como nos lembra a página-título de Casa-grande \& senzala), o autor tinha muito a dizer acerca de sexo, principalmente nos famosos capítulos sobre "o negro na vida sexual do brasileiro". Ele até mesmo tinha algo a dizer acerca das atitudes para com os animais, um tópico que os historiadores europeus somente começariam a levar a sério na década de 80 (cf. Freyre, 1936, cap. 4; Thomas, 1983). Ele também tinha algo a dizer acerca das crianças. Em 1921, o jovem confidenciou a seu diário sua ambição. "O que eu desejaria era escrever uma história como suponho ninguém ter escrito com relação a país algum: a história do menino brasileiro - da sua vida, dos seus brinquedos, dos seus vícios -, desde os tempos coloniais até hoje". Entre 1921 e 1930, a versão publicada do diário de Freyre refere-se ao projeto da história da criança no Brasil não menos do que sete vezes. Quatro dos artigos que escreveu para o Diário de Pernambuco nos anos 20 tratavam da infância, das crianças e seus livros e brinquedos. A história da criança atraiu seu interesse por si mesma, como uma desculpa para discutir sua própria infância, e como um microcosmo da cultura brasileira.

Embora Freyre nunca tivesse realizado seu plano original, não o abandonou completamente. Se voltamos para Casa-grande \& senzala, logo fica óbvio que fragmentos substanciais do "projeto secreto" estão embutidos no texto, indo das bonecas, pipas, piões, bolas e outros brinquedos e jogos das 
crianças brancas, negras e índias até o "sadismo patriarcal", os estudos e a disciplina dos colégios jesuítas e a breve discussão sobre a educação das meninas. Freyre argumenta, como Philippe Ariès iria fazer no caso da Europa moderna nascente, que no Brasil colonial meninos com dez anos de idade eram "obrigados a se comportarem como gente grande" (cf. Freyre, 1933, p. $215 \mathrm{ss}, 613 \mathrm{ss}, 632 \mathrm{ss})$.

Outros traços do projeto sobre a infância podem ser observados em Sobrados e Mucambos, que devotou um capítulo a "pais e filhos", opondo as atitudes para com os bebês (vistos como anjos), os infantes (vistos como diabos) e os meninos de dez ou mais anos (vistos como pequenos adultos) (cf. Freyre, 1936, p. 87 ss). Um ensaio posterior sobre o período 1825-1925 desenvolveu o tema dos "meninos quase sem meninice" (cf. Freyre, 1941a, esp. 151 ss). Ordeme Progresso retornou à infância repetidamente, enfatizando a "liberação" das crianças nesse período e também discutindo mais uma vez novos brinquedos, jogos e roupas (cf. Freyre, 1959, p. cxlix, clvii, 85 ss, 165 ss, 195 ss, 661 ss). Poderia ser útil reunir esses fragmentos e publicá-los. Com um pequeno exagero, o projeto da criança poderia ser descrito como o pai do trabalho maduro de Freyre.

De modo geral podemos comparar o interesse de Freyre pela história do cotidiano social, como ele ocasionalmente a chamou, com a preocupação corrente com o cotidiano, e seu interesse na história íntima com o que os historiadores franceses Georges Duby e Philippe Ariès chamaram histoire de la vie privée (cf. Freyre, 1975, p.147). Embora não tenha usado o termo "mentalidades", Freyre certamente esteve interessado em "ethos" e "valores" (cf. Freyre, 1937, p. 219; 1971, p.18).

A nouvelle histoire francesa fez uso de novas fontes de modo a responder às novas questões que seus praticantes colocavam para o passado. Um exemplo famoso é aquele do uso, por Le Roy Ladurie, dos exames médicos que sobreviveram em arquivos militares para um estudo sobre a história do corpo no início do século XIX que opunha os recrutas altos do norte aos recrutas mais baixos e subnutridos do sul (cf. Aron, Dumond \& Ladurie, 1972). Analogamente, o trabalho de Freyre recorreu a um âmbito extraordinariamente amplo de fontes - como ele foi o primeiro a apontar no prefácio à primeira edição de Casa-grande \& senzala.

Este não é o lugar para discutir se Freyre usou ou não fontes tais como relatos de viajantes ou jornalistas de modo suficientemente crítico ${ }^{4}$. O que precisa ser aqui enfatizado é sua disposição de ir além do âmbito relativamente estreito de documentos usados pela maioria de seus predecessores. Seu uso das descrições de escravos fugitivos - inseridas nos jor-

Sobre esse problema, cf. Maria Lúcia G. Pallares-Burke (1994).

5 Cf. Freyre (1933), desenvolvido em Freyre (1963). nais por seus proprietários - de modo a reconstruir a aparência física da população escrava é um notável tour de force, assim como o estudo dos recrutas franceses por Le Roy Ladurie ${ }^{5}$.

A "nova história" francesa baseou sua pretensão de novidade não apenas na descoberta de novos objetos de estudo, mas também no desen- 
volvimento de novas abordagens e métodos, freqüentemente em associação com outras disciplinas. Entretanto, como é bem conhecido, uma abordagem multidisciplinar desse tipo foi praticada por Gilberto Freyre já nos anos 30. Ele descreveu seus livros como contribuições à "sociologia" e à "antropologia" assim como à história social (cf. Freyre, 1933, prefácio à primeira edição). Ele tinha familiaridade com a tradição sociológica de Comte, Marx e Spencer, via Durkheim, até Max Weber, Georg Simmel e Vilfredo Pareto (cf. Freyre, 1975, p. 5, 12, 44, 79, 147, 225). Uma das mais conhecidas características da biografia intelectual de Freyre é sua descoberta do trabalho do antropólogo alemão-americano Franz Boas sobre raça e cultura, sem esquecer a cultura da cozinha (cf. Freyre, 1933, prefácio à primeira edição; 1939 ou 1969, p. 99-100; 1975, p. 88 e 147; Lima, 1989, p. 195 ss). Ele também citou outros antropólogos, entre eles Edward Tylor, Bronislaw Malinowski, A. R. Radcliffe-Brown (acerca de quem escreveu um ensaio) e Melville J. Herskovits (que foi seu colega de estudos em Columbia e compartilhou seu interesse nas culturas afro-americanas) (cf. Freyre, 1942).

Os fundadores da escola dos Annales, Marc Bloch e Lucien Febvre, estavam interessados no que eles chamavam "psicologia histórica" e estudaram a psicologia de Henri Wallon, embora negligenciassem Freud. Freyre, por outro lado, referiu-se em Casa-grande \& senzala e em outras obras não apenas a Freud (que o atraía porque "explica mistérios de minha meninice"), mas também a monografias sobre a psicologia da infância e da família de discípulos de Freud tais como Flügel, Moll e Pfister (cf. Flügel, 1921; Moll, 1912; Pfister, 1924). As referências não são casuais, pois a idéia de uma relação sado-masoquista entre senhor e escravo tem um papel central no estudo de Freyre.

Falar das "antecipações" de Freyre à década de 60 em diante é colocar um problema; não resolvê-lo. Como Freyre chegou a desenvolver sua marca particular de história social? Qual foi sua via intelectual para a casa grande? Que rota ele seguiu pelas mansões e choupanas do Brasil colonial? Embora seu contato com a cultura francesa tenha sido para ele de grande importância, alguns nomes franceses óbvios serão mencionados aqui apenas para serem rejeitados como influências: Lucien Febvre, Marc Bloch, Fernand Braudel e Paul Vidal de la Blache.

Em 1930, quando Freyre começou a trabalhar em Casa-grande \& senzala, Bloch e Febvre ainda não tinham estabelecido suas reputações internacionais e Fernand Braudel, um mestre-escola na Argélia, era ainda virtualmente desconhecido. Foi somente no final da década de 30, quando Braudel veio à USP, que ele e Freyre encontraram-se e descobriram seus interesses em comum (cf. Novais, 1994).

A avaliação de Casa-grande \& senzala por Braudel no periódico 
Mélanges d'histoire sociale - mais conhecido pelo nome posterior de Annales - foi calorosa (cf. Braudel, 1943) ${ }^{6}$. Isso não chega a surpreender, pois o livro de Freyre é braudeliano antes de Braudel em sua preocupação com os desenvolvimentos de longa duração e com o que o historiador francês chamou "histoire totale" e o brasileiro "um social total" (cf. Freyre, 1975 p. 222; Westphalen, 1983).Um futuro membro do grupo dos Annales, Marc Ferro, lembra de um seminário numa pequena sala da Sorbonne no decorrer do qual Braudel apresentou um livro de Freyre e explicou sua importância (citado em Daix, 1995, p. 220). Freyre e o mestre de Braudel, Lucien Febvre, também encontraram-se no Brasil e descobriram seu interesse em comum na antropologia histórica e na psicologia histórica. Alguns anos depois, Febvre contribuiria com um prefácio apreciativo à tradução francesa de Casa-grande \& senzala (cf. Febvre, 1952, p. 9-21) . Outros membros da "missão" cultural francesa em São Paulo que se interessaram pelas contribuições de Freyre à história social foram Paul Arbousse-Bastide e Roger Bastide (cf. ArbousseBastide, 1940; Bastide, 1960).

A comparação com Febvre e Braudel revela uma ausência significativa no trabalho de Freyre: a geografia histórica ou humana do tipo praticado por Paul Vidal de la Blache. Quão diferente teria sido Casa-grande \& senzala se seu autor tivesse descoberto Vidal? Entretanto, Freyre logo preencheu esse vazio. Por volta de 1935 ele estava suficientemente interessado por Vidal para usar seu Tableau géographique de la France num curso sobre "sociologia regional" que ministrou na Universidade Federal do Rio de Janeiro (cf. Chacon, 1989, p. 114).

Freyre logo abandonou Vidal por uma abordagem alternativa. Seu Nordeste foi um ensaio de "ecologia social" que examinou a influência da cana de açúcar na paisagem, nos animais e nos humanos da região (cf. Freyre, 1937). Onde Braudel foi atraído, talvez significativamente, por uma geografia relativamente estática, o entusiasmo de Freyre - como os sociólogos da Escola de Chicago - foi dirigido para uma ecologia mais dinâmica (cf. Freyre, 1937; Chacon, 1993, p. 260 ss). Esse interesse parece ter crescido a partir de seu amor pelas árvores e sua preocupação, expressa tão cedo quanto 1925 , pela "devastação da floresta" no Brasil?.

${ }^{6}$ Cf. a introdução de Braudel à tradução italiana de Casa-grande \& senzala, Padroni e Schiavi (1958, p. ix$\mathrm{xi}$,) e as referências a Freyre em Fernand Braudel (1966, p. 1, 108, 308).

7 Diário de Pernambuco, 1 de fevereiro de 1925. Reproduzido em Freyre (1979, 2, p. 115).
Freyre visitou a França pela primeira vez em 1922. Foi para ele uma experiência decepcionante, diferentemente de sua estada em Oxford. Ele não encontrou Pound ou Joyce, como esperava. Assistiu a conferências na Sorbonne, incluindo aquelas do historiador da literatura Fortunat Strowsky, mas foi embora com uma pobre impressão do "espírito de burocracia intelectual" (cf. Freyre, 1975, p. 83, 88).

Apesar desses desapontamentos, o encontro de Freyre com a cultura francesa foi significativo. Seu diário oferece evidência preciosa dos livros franceses que ele leu e suas reações a eles. Esses livros não ofereceram precedentes ou modelos para seu trabalho, mas alguns deles proporcionaram algo mais vago, uma orientação ou inspiração. Ele se entusiasmou particularmente 
por Proust, cujo trabalho ele começou a ler em 1923. De modo previsível, o que especialmente lhe agradou em Proust foi sua evocação da infância (cf. Freyre, 1975, p. 137). Entre os escritores de não-ficção, Freire selecionou um pequeno grupo que lhe parecia particularmente inspirador. Esse grupo incluiu Auguste Comte, Émile Durkheim, Jules Michelet, Hippolyte Taine, Denis Fustel de Coulanges e os irmãos Goncourt. Algumas palavras acerca da relevância de seus trabalhos para os projetos de Freyre são, portanto, oportunas.

Como se poderia esperar de um intelectual brasileiro no começo do século XX, uma das inspirações de Freyre veio do positivismo francês. A idéia de que o desenvolvimento da sociedade reproduz o desenvolvimento do indivíduo foi central para Comte. Freyre não só leu Comte quando adolescente, mas escreveu também um artigo sobre a adolescência como "o período feudal na vida do homem" (Freyre, 1975, p. 16). Freyre expressou entusiasmo pelas sociologias de Émile Durkheim e de seu rival Gabriel Tarde, bem como pela análise política de Georges Sorel (cf. Freyre, 1975, p. 45, 79, 146147). A ênfase na harmonia ou consenso cultural e social tão freqüentemente notada - e criticada - em Casa-grande \& senzala pode ser descrita como amplamente durkheimiana.

Entre os historiadores, Freyre escolheu Jules Michelet, cuja descrição de seu próprio trabalho como "ressurreição" histórica do passado assumiu. Uma descrição reveladora de seu projeto para a história da infância apresentou esse projeto como a combinação de um estudo histórico com "um livro sobre a minha própria meninice" (Freyre, 1975, p. 139). Não é, pois, surpreendente que ele admirasse Michelet, para quem é notória a dificuldade em distinguir entre os eventos de sua própria vida e os eventos históricos dos quais fazia a crônica (cf. Mitzman, 1990, p. 77 ss, 125 ss). Deve-se acrescentar que Michelet também escreveu algumas poucas páginas fascinantes sobre a história da infância e também que ele teve uma influência importante sobre a nova história francesa, em particular sobre Lucien Febvre (cf. Mitzman, 1990, p. 96 ss; Febvre, 1946).

Fustel des Coulanges foi um ilustre historiador do mundo antigo. Sua relevância para Freyre pode não ser imediatamente aparente, mas seu estudo clássico da cidade antiga tinha muito a dizer sobre a história da família (cf. Freyre, 1975, p. 6, 49, 146, 177; Coulanges, 1864). Quanto a Taine, sua History of English literature (efetivamente uma história cultural da Inglaterra) estava organizada em torno da intersecção entre "raça", "meio" e "momento". Embora Freyre tenha rejeitado esse paradigma, ele foi de óbvio interesse para ele (cf. Taine, 1863).

A melhor analogia francesa ao trabalho de Freyre antes do nascimento dos Annales foi provavelmente a "história da vida privada" praticada pelos irmãos Goncourt. Freyre estava efetivamente lendo os Goncourt com entusiasmo por volta de 1922, quando pensou em imitar sua histoire intime. Quando leu pela primeira vez Proust, interpretou À la recherche $d u$ temps perdu como um projeto paralelo (cf. Freyre, 1975, p. 136). Hoje, os 
Goncourt freqüentemente não são levados a sério como historiadores. Tendem a ser diminuídos como amadores e popularizadores que escrevem apenas para entreter. Contudo, eles tinham suas próprias idéias sobre a escrita da história. No prefácio do estudo sobre as amantes de Luís XV, publicado em 1860, os Goncourt argumentaram em favor de uma história "nova" ou "social", uma história da vida privada que faria justiça à "mulher, esse agente histórico altamente desconsiderado". Essa nova história, segundo os Goncourt, utilizaria uma ampla variedade de fontes, tais como jornais, novelas e pinturas (cf. Goncourt, 1860, p. ix-xii). Ambas preocupações, com a mulher e com o uso de jornais, também são marcas do trabalho de Freyre. Se ele tem tanto em comum com os praticantes da nouvelle histoire, a explicação óbvia é em termos de uma ancestralidade intelectual comum.

III

Fascinado como foi pelos franceses, o jovem Freyre também permaneceu aberto a idéias oriundas de outras fontes, como já vimos. Poderse-ia descrever seu trabalho como uma forma de ecletismo multidisciplinar, não propriamente síntese, mas sincretismo. Ele não apenas pregou a "hibridização", mas a praticou por toda sua vida intelectual. Ele foi uma espécie de esponja intelectual que podia sugar com grande facilidade tanto as idéias como a informação a partir de uma multiplicidade de fontes. Seu problema era conceber um sistema de referência para todas essas idéias.

Gostaria de sugerir que esse sistema de referência teria vindo, em parte, da "new history" americana. O projeto da infância ocorreu a ele enquanto vivia nos Estados Unidos e estudava sociologia, antropologia, psicologia e história na Universidade Columbia, num momento em que essas disciplinas estavam mais próximas entre si do que se tornaram na geração seguinte. Foi nesse ambiente de apoio que ele desenvolveu suas idéias de uma "história sociológica, psicológica, antropológica". Que Freyre aprendeu muito com Franz Boas é um ponto por demais conhecido para ser desenvolvido aqui. Entretanto, ele também registrou seu interesse no trabalho dos historiadores sociais, principalmente Harry Elmer Barnes, Charles Beard e James H. Robinson, que ele descreveu como "um dos grandes renovadores do estudo da história" (cf. Freyre, 1975, p. 59; 1934, p. 36 ss, 48).

Barnes, Beard e Robinson foram líderes do movimento da chamada "New History", um movimento para o qual Robinson escreveu uma introdução ou manifesto (cf. Robinson, 1912; Hendricks, 1946). Na época em que Bloch era ainda um estudante e Febvre ainda não tinha desenvolvido sua abordagem característica, os historiadores novos americanos estavam em campanha em favor de uma história que tratasse de todo aspecto da atividade humana e se valesse das descobertas de antropólogos, economistas, psicólogos e sociólogos. O movimento teve menos impacto do que seu sucessor francês acabaria tendo e nunca produziu uma obra-prima como o estudo de Braudel 
sobre o Mediterrâneo (cf. Robinson, 1912; Hendricks, 1946). O que ele podia oferecer ao jovem Freyre, diferentemente dos franceses que ele estava estudando na mesma época, era um sistema de referência multidisciplinar, que permitia que ele assimilasse idéias de diferentes fontes transformando-as em um todo coerente. Na história global da história social, Freyre merece ser lembrado como um vínculo importante na cadeia viva que une a "new history" com a nouvelle histoire. O caminho de Nova Iorque a Paris passou por Recife.

Tradução de Pablo Rubén Mariconda Recebido para publicação em janeiro/1997

BURKE, Peter. Gilberto Freyre and the new history. Tempo Social; Rev. Sociol. USP, S. Paulo, 9(2): 1 12, october 1997.

ABSTRACT: The point of departure of this article is a series of similarities between the 'new history' associated with the French journal Annales, and the social history, psycho-history or historical anthropology of Gilberto Freyre; similarities which range from a concern with material culture (food, clothes and housing), to an interest in mentalities and the history of childhood, a theme which preoccupied Freyre in the years before he published Casa-grande \& senzala. These similarities of approach were recognized by both Febvre and Braudel when they discovered Freyre's work in the later 1930s. Freyre was not imitating Annales, nor were Febvre and Braudel imitating him. He learned his interdisciplinary style at Columbia, a centre of the American 'new history' movement of the beginning of the century. However, Freyre was, like Febvre, admirer of Michelet. His 'historia intima' also owes something to the Histoire Intime practised by the Goncourt brothers, the importance of which in the history of historical writing has not been sufficiently recognized.

\section{REFERÊNCIASBIBLIOGRÁFICAS}

Arbousse-Bastide, Paul. (1940) Prefácio. In: Freyre, Gilberto. Um engenheiro francês no Brasil. Rio de Janeiro, José Olympio.

ArIÈs, Philippe \& Duby, Georges (eds.). (1987-1991) History of private life. Tradução da edição original de 1985-1987. 5 vols. Cambridge, Harvard University Press. . (1960) L'enfant et la vie familiale en l'ancien regime. Paris, Plon. . (1982) Un historien de dimanche. Paris, Seuil.

UNITERIMS: historiography, psychohistory, historical anthropology, material culture, mentalities. 
Aron, Jean-Pierre, Dumond, Pierre \& Ladurie, Emmanuel Le Roy. (1972) Anthropologie du conscrit français: d'après les comptes numeriques et sommaires du recrutement de l'armée (1819-1826), presentation cartographique. Paris, La Haye, Mouton.

BARDET, Jean-Pierre et alii. (1971) Le bâtiment: enquête d'historie économique XIV-XIX siecles. Paris, La Haye, Mouton.

BASTIDE, Roger. (1960) Les religions africaines au Brésil: contribution a une sociologie des interpenetrations de civilisation. Paris, PUF.

BRAUDEL, Fernand. (1943) À travers un continent d'histoire: le Brésil et l'oeuvre de Gilberto Freyre. Mélanges d'histoire sociale 4. Paris, Annales d'histoire sociale: 3-20.

. (1965) Introdução à tradução italiana de Casa-grande \& senzala, Padroni e Schiavi. Torino, G. Einaudi.

. (1966) La Méditerranée et le monde méditerranéen à l'époque de Philippe II. 2 vols. $1^{\text {a ed. }}$ 1949. Paris, A. Colin.

. (1967) Civilisation matérielle et capitalisme. Paris, A. Colin.

BURKE, Peter. (1981) Material civilisation in the work of Braudel. Itinerario: $37-43$.

Chacon, Vamireh. (1989) A luz do norte. Recife, Companhia Editora Nacional. (1993) Gilberto Freyre: uma biografia intelectual. Recife, Companhia Editora Nacional.

Coulanges, Numa Denis Fustel de. (1864) La cité antique. Paris, Hachette.

DaIx, Pierre. (1995) Braudel. Paris, Flamarion.

Duby, Georges \& Perrot, Michèle (eds.). (1992-1994) The history of women. Tradução da edição original de 1990-1992. 5 vols. Cambridge, Harvard University Press.

Febvre, Lucien Febvre (ed.). (1946) Michelet. Genève/Paris, Droz.

. (1952) Brésil, terre d'histoire. In: FreYre, Gilberto. Les maîtres et les esclaves. Paris, Gallimard.

FLANDRIN, Jean-Louis. (1975) Les amours paysannes. Paris, Gallimard/ Julliard. . (1983) Un temps pour embrasser. Paris, Plon.

FLÜGEL, John Carl. (1921) Psychoanalytic history of the family. London, The International Psychological Press.

FREYRE, Gilberto. (1925) Região, tradição e cozinha. In: . (1941b)

Região e tradição. Rio de Janeiro, José Olympio, p. 195-213.

. (1933) Casa-grande \& senzala. Rio de Janeiro, Maia \& Schmidt.

. (1934) O estudo das ciências sociais nas universidades americanas.

Recife, Opúsculo. 
. (1935) Artigos de jornal. Recife, Casa Mozart.

- (1936) Sobrados e mucambos. São Paulo, Companhia Editora Nacional.

. (1937) Nordeste. Rio de Janeiro, José Olympio.

- (1939) Açúcar: algumas receitas de doces e bolos dos engenhos do Nordeste. Rio de Janeiro, José Olympio.

. (1941a) Aspectos de um século de transição. In:

Região e tradição. Rio de Janeiro, José Olympio, p. 107-194.

. (1941b) Região e tradição. Rio de Janeiro, José Olympio.

. (1942) O antropologista inglês Radcliffe-Brown. In: . Ingleses. Rio de Janeiro, José Olympio, p. 151-155.

. (1959) Ordem e progresso. 2 vols. Rio de Janeiro, José Olympio.

- (1963) O Escravo nos anúncios de jornais brasileiros do século $X I X$. Recife, Imprensa Universitária.

. (1965) Padroni e Schiavi. Torino, G. Einaudi.

- (1969) Açúcar: em torno da etnografia, da história e da sociologia do doce no nordeste canavieiro do Brasil. $2^{\text {a }}$ edição revista e ampliada. Rio de Janeiro, Instituto do Açúcar e do Álcool.

. (1971) A casa brasileira. Rio de Janeiro, Grifo Edições.

- (1975) Tempo morto e outros tempos: trechos de um diário de adolescência e primeira mocidade, 1915-1930. Rio de Janeiro, José Olympio.

. (1979) Tempo de Aprendiz. 2 vols. São Paulo, IBRASA/INL.

Goncourt, Edmond \& Jules. (1860) Les maîtresses de Louis XV. Paris, Firmin Didot.

Hemandiquer, J.-J. (ed.). (1970) Pour une histoire de l'alimentation. Paris, Plon.

HendRICKs, L.V. (1946) J.H.Robinson. New York, King's Crown Press.

LAdurIE, Emmanuel Le Roy. (1975) Montaillou village occitan. Paris, Gallimard.

Le Goff, Jacques \& NorA, Pierre (eds.). (1974) Faire de l'histoire. 3 vols. Paris, Gallimard.

Lima, Luiz Costa. (1989) A aguarrás do tempo. Rio de Janeiro, Zahar.

MANDROU, Robert. (1964) Introduction à la France moderne: essai de psychologie historique. Paris, Albin Michel.

Mitzman, Arthur. (1990) Michelet, historian. New Haven, Yale University Press.

MoLL, Albert. (1912) The sexual life of the child. London, AMS Press. 
NovaIs, Fernando. (1994) Braudel e a "missão francesa". Estudos Avançados, São Paulo, 8(22): 161-166.

Pallares-Burke, Maria Lúcia G. (1994) A spectator in the tropics: a casestudy in the production and reproduction of culture. Comparative Studies in Society and History, Cambridge University Press, 36: 676-701.

Pfister, Oscar. (1924) Love in children. Tradução da edição original de 1922. London, Allen and Unwin.

Revel, Jacques \& Peter, Jean-Pierre. (1974) Le Corps. In: Le Goff, Jacques $\&$ Nora, Pierre (eds.). Faire de l'histoire. Vol. 3. Paris, Gallimard. p. 169-191.

Robinson, James H. (1912) The new history. New York, Macmillan.

Roche, Daniel. (1989) La culture des apparances. Paris, Fayard.

TAINE, Hyppolite. (1863) Histoire de la littérature anglaise. Paris, Hachette.

Thomas, Keith. (1983) Man and the natural world. London, Allen Lane.

Vovelle, Michel. (1982) Idéologies et mentalités. Paris, Maspero.

Westphalen, Cecília Maria. (1983) Um modelo de história social: o de Gilberto Freyre. In: MоттA, Roberto (ed.). Anais do Seminário de Tropicologia, Recife, p. 236-237. 